\title{
Ectopic pregnancy in animals and humans
}

\author{
Juan Manuel Corpa \\ Departamento Atención Sanitaria, Salud Pública y Sanidad Animal (Histología y Anatomía Patológica), \\ Facultad de Ciencias Experimentales y de la Salud, Universidad Cardenal Herrera-CEU, Edificio Seminario, \\ s/n. 46113 Moncada (Valencia), Spain
}

Correspondence should be addressed to J M Corpa; Email: jmcorpa@uch.ceu.es

\begin{abstract}
Ectopic pregnancy denotes a pregnancy occurring elsewhere than in the cavity of the uterus. This pathology has been recognised for years and it causes numerous maternal deaths during the first trimester of pregnancy. While this condition is wellknown in humans, it is rarely diagnosed in animals. However, the causes and mechanisms leading to an ectopic implantation of the ovum are not always clearly defined in humans or animals. Two types of ectopic pregnancy are mainly recognized: (1) tubal pregnancy occurs when an oocyte is fertilized and then remains in the oviduct and (2) abdominal pregnancy occurs when the gestation develops in the peritoneal cavity. The latter may be subdivided into two subtypes: the primary form, when a fertilized oocyte enters the peritoneal cavity and becomes attached to the mesentery or abdominal viscera, and the secondary form, which follows the rupture of an oviduct or the uterus after the fetus has been implanted, and the fetus is expelled into the peritoneal cavity. Cornual, ovarian and cervical ectopic locations are less frequent. Several differences exist in ectopic pregnancies between human beings and animal species. While abdominal pregnancy has been described in both human and animal species, tubal ectopic pregnancies would appear to be restricted to primates. Other than anecdotal cases, this pathological condition does not occur in laboratory, domestic or farm animals. Several factors are described as being the cause of these differences.

Reproduction (2006) $131631-640$
\end{abstract}

\section{Introduction}

In humans, ectopic pregnancy is an important pathology that was recognised over 900 years ago (Albucassis quoted by Buckley \& Caine 1979). It is one of the major causes of maternal death during the first trimester of pregnancy, causing $10 \%$ of all maternal deaths and $16 \%$ of haemorrhages in pregnancy. Its mortality rate is 3 per 1000 cases (De Cecco et al. 1984). This condition has undergone a dramatic increase over the last decades (Wolfman \& Holtz 1983), although the ectopic pregnancy rate actually seems to be stabilizing (Van Den Eeden et al. 2005) or even declining in some types of ectopic pregnancy (Coste et al. 2000). Nevertheless, epidemiological data vary depending on the country studied. Van Den Eeden et al. (2005) reported an annual ectopic pregnancy rate of 20.70 per 1000 reported pregnancies, and of 1.03 per 1000 women aged $15-44$ years.

While this condition in humans is a well-known pathology to gynaecologists in all its clinical characteristics, it is still rarely diagnosed in animals. No detailed epidemiological studies on ectopic pregnancy have been conducted on animals. In laboratory animals, a low incidence of abdominal pregnancies $(0.05 \%)$ was found in pigs (Hong \& Armstrong 1978). However, Buckley \& Caine (1979) described a high abdominal pregnancy incidence rate in a relatively small hamster colony. The incidence is variable in commercially produced rabbits on different farms. A one-year study on the main causes of rabbit doe discard was performed on two farms where incidence rates of $7.8 \%$ and $1.6 \%$ respectively were reached for abdominal pregnancies (Segura Gil et al. 2004). Additionally, four abdominal pregnancies have been identified among 70 eliminated adult necropsied does (5.7\%) in 6 months from another farm (J M Corpa unpublished observations).

The causes and mechanisms leading to an ectopic implantation of the ovum in animals and humans are not equally or always clearly defined (De Cecco et al. 1984). Although different studies seem to indicate that ectopic pregnancy is an infrequent condition, numerous reports in both humans and animals exist. This denotes the enormous interest of an ectopic pregnancy given its clinicalpathological and scientific repercussions. The objective of this paper is to review the knowledge on ectopic pregnancies in animals and humans, and to establish the main differences between them. 


\section{Ectopic pregnancy types}

No uniform criterion of ectopic pregnancy classification exists in humans and animals. Various criteria have been unified to enable a didactic study of ectopic pregnancies.

Ectopic, or extrauterine pregnancy, denotes a pregnancy that occurs elsewhere than within the uterine cavity. Two main ectopic pregnancy types are recognized. (1) Tubal pregnancy occurs when an oocyte is fertilized and then remains in the oviduct because of numerous causes that prevent its arrival in the uterus. Various subtypes have been distinguished depending on the location: fimbrial, ampulla and isthmus (Fig. 1). (2) Abdominal pregnancy occurs when the gestation develops in the peritoneal cavity. It may be subdivided into two subtypes: primary and secondary. In the primary form, an oocyte or a retrograde oocyte that is directly lost from the fimbrial or the oviduct respectively, is fertilized in the abdominal cavity and develops there, or a fertilized retrograde ova enters the peritoneal cavity and becomes attached to the mesentery or abdominal viscera (Fig. 2). In a true primary form, placentation must exist on either a peritoneal or omental surface. Secondary abdominal pregnancies follow the rupture of an oviduct or the uterus (Fig. 3) after the fetus has been implanted (Smith et al. 1989), either due to external trauma or internal pressure (Owensby et al. 2001). The fetuses are expelled into the peritoneal cavity (Fig. 4). Histologically, the fetuses usually show a well-organized fibrous membrane surrounding them and a moderate autolysis of the internal organs (Fig. 5). Three possibilities have been described in a secondary abdominal pregnancy: (a) the fetus escapes into the abdominal cavity following a uterine rupture, but placental attachments are retained (Lederer \& Fisher 1960), (b) the fetus develops

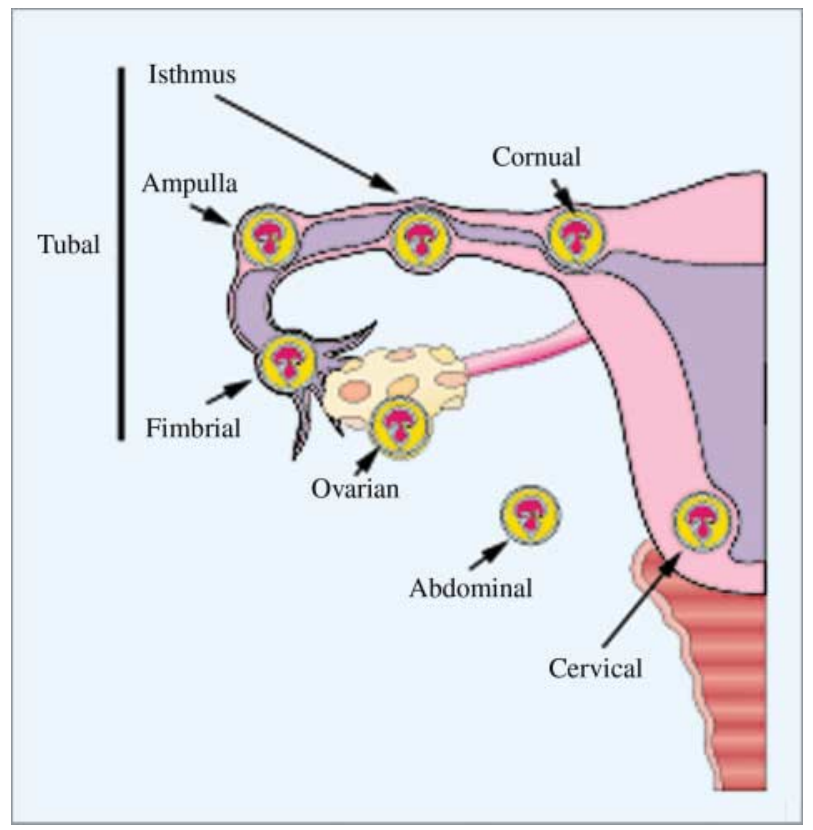

Figure 1 Sites of ectopic pregnancy implantation.

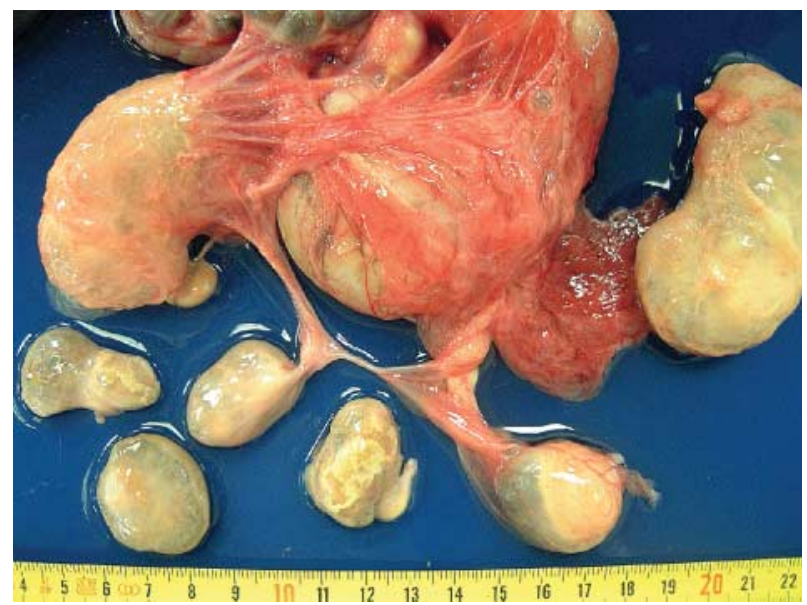

Figure 2 Rabbit doe. Eight different sized fetuses (black asterisks) attached to stomach serosa (white asterisk) and floating free in the abdominal cavity.

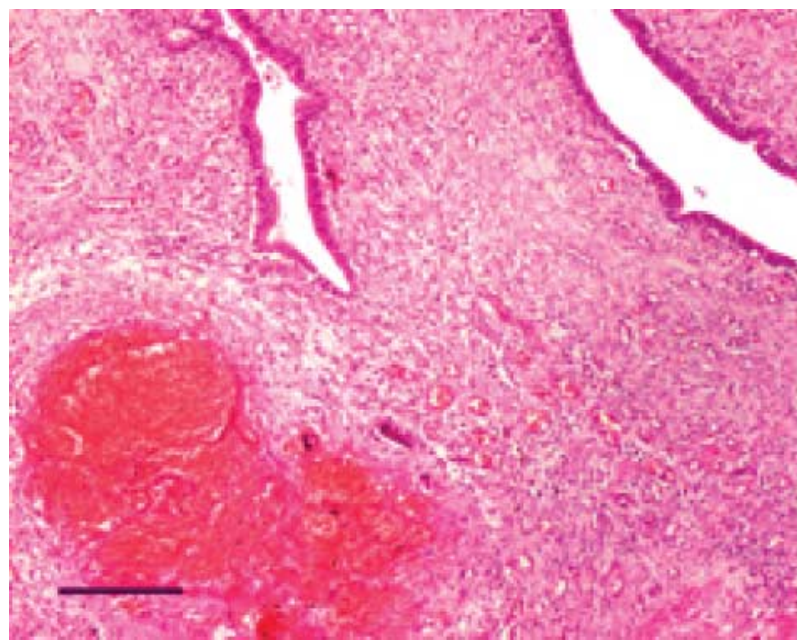

Figure 3 Rabbit doe. Haemorrhage of endometrium associated with uterine horn rupture. Haematoxylin-eosin. Scale bar: $100 \mu \mathrm{m}$.

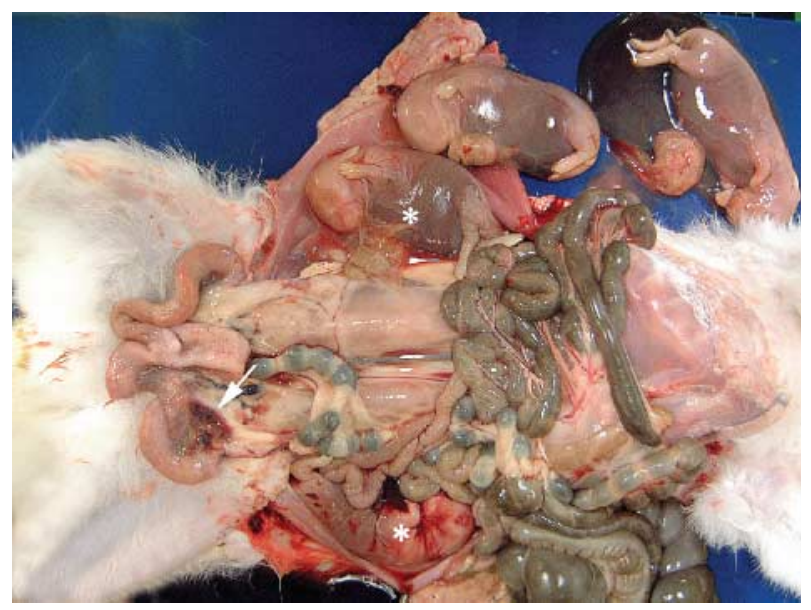

Figure 4 Rabbit doe. Recent abdominal pregnancy secondary to a left horn rupture (arrow). Two fetuses showed placental attachments (asterisks) to different abdominal surfaces. 


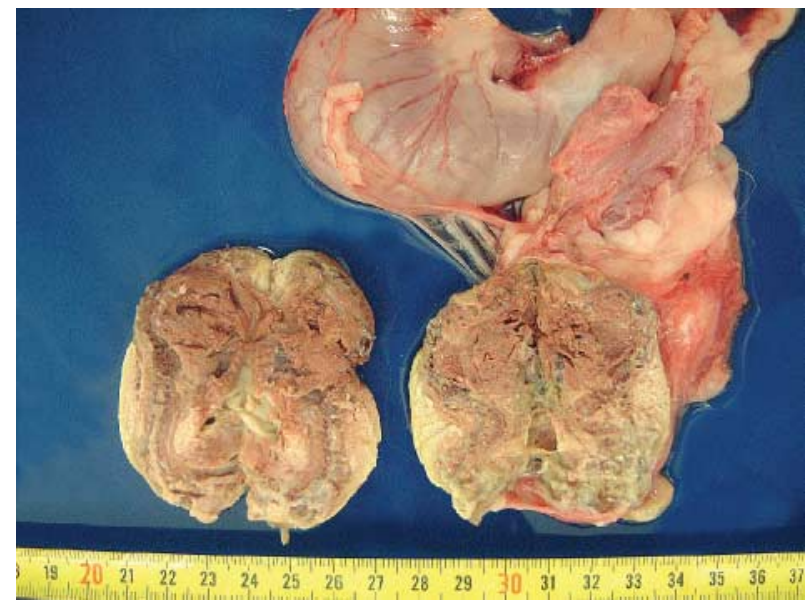

Figure 5 Fetus surrounded by a well-organized fibrous membrane composed of homogenous eosinophilic material and fibroblasts. Although internal tissues show a moderate autolysis, rachis (white arrow), tracheal cartilages (black arrow) and lungs (asterisk) can be easily differentiated. Haematoxylin-eosin. Scale bar: $500 \mu \mathrm{m}$.

further with a gradual and eventual complete reimplantation of the placenta in the abdominal cavity (Bunte \& Hildebrandt 1975) or (c) an internal abortion may occur in which the conceptus escapes into the abdominal cavity, along with a loss of placental attachment (Madani \& Tirgari 1984). Other less frequent ectopic locations are the cornual, ovarian and cervical kind, where an extrauterine pregnancy may develop (Ginsburg et al. 1989, Bouyer et al. 2002, Kraiem et al. 2004, Tarim et al. 2004).

\section{Tubal pregnancies}

A tubal pregnancy is frequently encountered in human gynaecologic practice in contrast to other species. The rarity of observed tubal pregnancies in animals other than humans suggests that either tubal implantation rarely occurs, or that the resultant pregnancies do not survive long enough to cause observable clinical signs of this condition. Recently, it has been proposed in women with extrauterine pregnancy that the leucocytic infiltrate in the area of ectopic implantation may cause gradual destruction of the ectopically located trophoblast (Kucera et al. 2004). It has been reported that the low frequency of non human primate tubal pregnancies may be due to the inability of the ectopically implanted placenta to maintain the pregnancy for an adequate period of time (Jerome \& Hendrickx 1982). Additionally, studies of tubal ligation in mice, rabbits, rats, sheep, and pigs have shown that embryos degenerate rather than implant in obstructed tubes (Heap et al. 1979b, Moore et al. 1992). Either the tubal environment is not conducive to embryonic development, secreting factors that prevent tubal implantation (Moore et al. 1992) for these non-primates, or perhaps the embryo confined to the tube is unable to carry out a maternal recognition of pregnancy. In many non-primates, embryonic signals alter both the amount and distribution of luteolysins secreted by the endometrium (Heap et al. 1979a, 1979b). However, this may require an intrauterine embryo; luteolysis occurs unless the embryonic signal is received, and the pregnancy cannot be maintained (Jerome \& Hendrickx 1982). It has also been proposed that the difference in the observed tubal pregnancy incidence between humans and non-human primates may be related to the degree of dependence that the pregnancy has on the functional status of the ectopic placenta in early gestation (Jerome \& Hendrickx 1982).

It has been reported that in humans an oviductal localization accounts for approximately $95-98 \%$ of all ectopic pregnancies, and that approximately $1 \%$ of oviductal pregnancies are bilateral (Levasseur 1983). Ectopic pregnancies residing in the distal two thirds of the tube are the most frequent, accounting for $85 \%$ to $95 \%$ of all tubal ectopic pregnancies (DeCherney \& Boyers 1985). Although the reported percentages are variable, it can be concluded that the most frequent oviductal segments involved are ampulla (42-70\%), isthmus (12-28\%), fimbriated end of oviduct $(7-17.4 \%)$, interstitial portion $(2-13 \%)$, oviductal stump $(2 \%)$, and other unknown locations (8\%) (Douglas 1963, Bouyer et al. 2002). Most oviductal pregnancies terminate within the first 2 to 3 months of implantation by haemorrhage, ablation of chorionic tissue, or by a rupture of the oviduct (Nicosia 1985).

In humans, the primary cause of tubal implantation is thought to be an impairment of tubal transport, often as a result of chronic inflammatory disease. It has been proposed (Iffy 1965) that in some cases of tubal pregnancy, menstrual flow might have caused a tubal reflux (with subsequent implantation) of embryos conceived after midcycle, and the secretion of chorionic gonadotrophin starts too late to prevent menstruation. Recently, it has been proposed that the vascular endothelial growth factor may be the angiogenic factor responsible for the implantation and placentation of an ectopic pregnancy in the human oviduct (Lam et al. 2004). The expression of various factors such as matrix metalloproteinases and tissue inhibitor of matrix metalloproteinases may have roles in regulating the controlled invasion of trophoblasts during implantation and placentation during tubal pregnancy (Bai et al. 2005).

Oviductal pregnancies are often misdiagnosed for abortion, pelvic inflammatory disease, ovarian cysts, and uterine leiomyomas. Unequivocal histological documentation of ectopic pregnancy requires the presence of chorionic villi or fetal tissues within the oviduct. A corroborating diagnostic finding is the presence of hypersecretory endometrium with atypical glands and large nuclei (Nicosia 1985).

It has not been possible to produce experimental tubal pregnancies in laboratory or farm species (Hunter 1998).

\section{Abdominal pregnancies}

Although abdominal pregnancy in humans has been scientifically reported since the 16th century (Kompanje 2005), 
this condition still causes controversy as to whether it is primary or secondary to a rupture of the uterus or oviduct. Histological studies of placentation, a mummified fetus and of either a ruptured uterus or oviduct are needed to establish the difference between primary and secondary forms (Nack 2000). It is known that the myometrium can regenerate, leaving little or no cicatricial tissue. This may explain the failure to find a uterine scar in some reports (Bunte \& Hildebrandt 1975, Segura Gil et al. 2004).

It is difficult to reconcile a primary abdominal pregnancy with the accepted hypothesis of the establishment of pregnancy. This requires the presence of the conceptus in the uterus 12 to 15 days after fertilization (Moor \& Rowson 1966a, 1966b), and the exchange of humoral agent(s) leading to corpus luteum maintenance (Bazer \& First 1983). The presence of either the conceptus or a mummified fetus is always attended by a retained corpus luteum, indicating a feto-maternal endocrine relationship (Madani \& Tirgari 1984).

Approximately $1.3 \%$ of ectopic pregnancies are abdominal (Bouyer et al. 2002), and they occur through direct implantation on to the peritoneal surface. Primary abdominal pregnancies have been described in a variety of extrapelvic organs, including omentum, liver, spleen, and the small and large intestines (Kalof et al. 2004, Onan et al. 2005).

Primary abdominal pregnancies are extremely rare, although they were reported for the first time in animals and women many years ago (Bland-Sutton 1904 and Maxwell et al. 1927 quoted by Buckley \& Caine 1979). Cases of secondary abdominal pregnancy have been reported in several animal species, and they have been experimentally induced in rabbits, guinea pigs (Bland \& Donovan 1965), rats (Bunte \& Hildebrandt 1975) and mice (Hreshchyshyn \& Hreshchyshyn 1964). In humans, secondary abdominal pregnancy is usually subsequent to tubal pregnancies with a rupture of the oviduct (Smith et al. 1974).

Death of the abdominal fetuses would occur when the crude placental attachment no longer provided sufficient nutrition through an inadequate blood supply (Buckley \& Caine 1979). The fact that abdominal fetuses can develop to an advanced stage (Fig. 6) without an elaborate placentation has been shown in pregnancy reports following ovariohysterectomy in humans and animals (Carrig et al. 1972, Crownover \& Yeargan 1976, Forbes 1989, Knott 1989, Peterson et al. 1997, Nack 2000). Two possible explanations have been proposed for ectopic pregnancy in spayed animals. First, it was thought that the physical handling of the fallopian tubes during surgery carried out shortly after coitus might have placed the fertilized ova into the abdomen. Secondly, the fetus was from a prior pregnancy, and it went unnoticed at the time of ovariohysterectomy (Carrig et al. 1972, Nack 2000). An abdominal pregnancy occurring subsequent to hysterectomy is recognized as a rare postoperative complication in human beings (Hanes 1964), although it has been reported that a history of tubal sterilization does not rule out the possi-

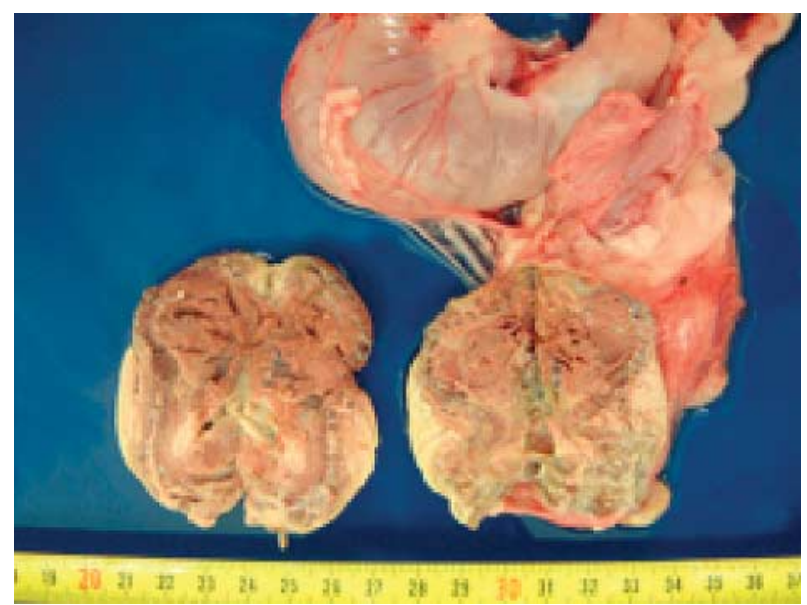

Figure 6 Rabbit doe. Secondary abdominal pregnancy. Two mummified fetuses with a well developed osseous structure and markedly autolysed parenchymatous organs. One of them was attached to the serosal surface of the stomach (right) and the other was free in the abdominal cavity (left).

bility of ectopic pregnancy, even many years after the procedure (Peterson et al. 1997).

Whereas abdominal pregnancy has been regularly reported to be compatible with full-term development in humans (Xiao et al. 2005), it is very rare or unknown in domesticated and laboratory species (Gosden \& Russell 1981). Only two references have been found of animals with abdominal pregnancy, where a caesarean was performed and the lambs and kittens were alive (Feeney \& Johnston 1983, Mitchell 1989).

Long-existing abdominal fetuses in women frequently become calcified, and these are called lithopedions (Bunte \& Hildebrandt 1975). Mineralized abdominal fetuses have been reported in monkeys (Bosu \& Barker 1980), dogs, cats (Bunte \& Hildebrandt 1975) and rabbits (Segura Gil et al. 2004).

\section{Ectopic pregnancy in animals}

Differences exist in the location of ectopic pregnancies in animals. Other than primates, where several cases of tubal pregnancies have been described, the abdominal cavity is the most frequent location of ectopic pregnancies. On the basis of the number of reports, it would also appear that differences exist between species.

\section{Primates}

Three cases of tubal pregnancy have been reported in primates: in a hamadryas baboon (Papio hamadryas) with apparent tubal placentation (Waldeyer, 1893, quoted by Jerome \& Hendrickx 1982), in a rhesus monkey (Macaca mulatta) implanted in the ampulla of the uterine tube, where an endocrine or neuromuscular defect affecting tubal transport was the proposed cause (Jerome \& Hendrickx 1982), and in a vervet (Cercopithecus aethiops) (Lapin \& Yakovleva 1963). 
Eight cases of abdominal pregnancy have been described in primates: owl monkey (Aotus trivirgatus) (Bunte \& Hildebrandt 1975), squirrel monkey (Saimiri sciureus) (McClure \& Chang 1975), rhesus monkey (Bosu \& Barker 1980), and baboon (Papio papio) (Schlabritz-Loutsevitch et al. 2004). The first three were diagnosed as being the result of a spontaneous uterine rupture, but the last, which had undergone a caesarean section in the past, showed no sign of uterine rupture or fistula. In this case, a primary ectopic pregnancy was suspected and the authors hypothesized that it was the result of a pathological implantation of a fertilized egg from an ovary, suggesting that previous caesarean sections are a risk factor for abdominal pregnancy (Schlabritz-Loutsevitch et al. 2004). In addition, two abdominal pregnancies were reported in rhesus monkeys (Myers 1972), and two extrauterine pregnancies were briefly reported in monkeys (Lapin \& Yakovleva 1963).

\section{Laboratory animals}

Ectopic pregnancies have also been described in other non-primate laboratory animals such as guinea pigs (Araujo 1964, Hong \& Armstrong 1978), rabbits (Smith et al. 1989, Arvidsson 1998, Beddow 1999, Owensby et al. 2001), hamsters (Buckley \& Caine 1979, Peters 1982), rats (Gosden \& Russell 1981, Polzenhagen et al. 1983), and mice (Bloch 1962, King et al. 1978). Abdominal pregnancies were diagnosed in all cases except for a rat (Polzenhagen et al. 1983) and a mouse (King et al. 1978), where ovarian and tubal pregnancies respectively were proposed. Primary and secondary ectopic pregnancies have been proposed in all reported species, although there was no clear diagnosis at times. Although the estimation of the time the ectopic pregnancy was indicated, it was always approximate and it oscillated between a period of days to 8 months in a rabbit with a primary abdominal pregnancy (Smith et al. 1989).

\section{Domestic animals}

The large number of references about ectopic pregnancies in domestic animals, mainly in cats, is striking. All cases were abdominal pregnancies (primary or secondary), and this condition has been described in several reports on spayed cats where the ectopic pregnancy was usually diagnosed in a routine exploration months after ovariohysterectomy (Carrig et al. 1972, Crownover \& Yeargan 1976, Forbes 1989, Knott 1989, Nack 2000). This late diagnosis, sometimes up to two years after conception (Lofstedt 1989), is due to the absence of clinical signs in the majority of cases. When present, clinical signs (decreased appetite, retching, vomiting, etc.) were usually associated with unrelated infections (Hannon 1981), mechanical interference with abdominal organs or with the necrosis of the ectopic tissue (Johnson 1986). No clear association exists between the duration for the ectopic fetus and the development of clinical signs (Nack 2000).
Except in spayed animals where a primary form was proposed, all other recorded cases were thought to be secondary due to an abnormal parturition associated with uterine rupture (De Nooy 1979, Johnson 1986, Palmer 1989), or with abnormal uterine anatomy (i.e. one uterine horn and a urachal remnant) (Hansen 1974). These abnormal structures would allow sperm to reach and fertilize an ovum, but they would not allow the uterine tract to receive the fertilized ovum (Nack 2000).

\section{Farm animals}

Only ten references have been found referring to ectopic pregnancies in farm animals: two in mares (Freytag 1972, Thursby-Pelham 1992), two in cows (Botcherby 1980, Hedge 1989), three in sheep (Davies 1982, Madani \& Tirgari 1984, Mitchell 1989) and three in farmed rabbits (Marcato \& Rosmini 1986, Rosell 2000, Segura Gil et al. 2004). Secondary abdominal pregnancies were diagnosed in all cases except in some does, where a primary pregnancy was suspected (Segura Gil et al. 2004), and in a mare where two 17-day-old concepti were found in a tubal location; the first migrated to a normal position within the uterine horn, and the second was seen to be resorbing during a second scanning (Thursby-Pelham 1992).

\section{Differences between humans and animals}

After reviewing the bibliography, the main conclusion is that several differences exist (incidence, pathogeny, location, clinical presentation, treatment, prognosis, etc.) in ectopic pregnancies between human and animal species.

Although abdominal pregnancies have been described in human and animal species, tubal ectopic pregnancies would appear to be restricted to primates. Other than anecdotal cases, this pathological condition does not occur in laboratory, domestic or farm animals (Hunter 2002). It has been reported that these differences may be influenced by a number of factors.

\section{Anatomical factors}

\section{Uterus and oviduct}

It has been reported that the anatomical differences between the simplex uterus in primates, compared with either a bicornuate or a bipartite uterus in laboratory and farm species, may be relevant. There is no clear-cut distinction between the endometrium and endosalpinx in the intra-mural segment, and there is evidence to indicate that not only does fluid from the tubal lumen enter the uterus, but also that the uterine fluid may retrogradely pass into the tubes of primates. Accordingly, if a mixing of tubal and uterine fluids occurs, it may not be essential for a developing morula to pass to the uterus in order to gain access to metabolic substrates present in uterine fluid. Nonetheless, there seems to be a marked difference 
between primates and domestic or laboratory animals in the potential access of the uterine fluid to the fallopian tubes. The uterine fluid of the golden hamster damages the membranes of recently ovulated (tubal) eggs (Hunter 1998) and additionally it has been hypothesized that rabbit endosalpinx secretes a factor that prevents tubal implantation (Moore et al. 1992).

\section{Placentation}

Although primary abdominal pregnancies have been reported in domestic species, no viable fetoplacental units outside an intact uterus have been found during the latter half of pregnancy. The type of placentation in cats does not lend itself to produce a viable extrauterine pregnancy. Therefore, true extrauterine viable pregnancy does not seem likely in cats (Nack 2000). It has been proposed that viable extrauterine fetuses would seem unlikely in terms of the form of placentation in carnivora, despite its relative intimacy in comparison with other domestic species (Lofstedt 1989). By contrast, human beings have an invasive type of placentation (Climent \& Bascuas 1989), and this is probably the reason why human fetoplacental units can develop to term in extrauterine pregnancies (Lofstedt 1989).

\section{Physiological factors}

It has been reported that the different incidence of extrauterine pregnancy in women and domestic animals may be influenced by some of the following factors (Lofstedt 1989). (1) The ability of the human zygote to cleave in vitro without the need for tubal or uterine factors. This is in contrast to other mammalian zygotes, in which at least one cleavage stage cannot be pursued (Thibault 1972). (2) The more active role of the blastocyst in implantation in women. This, together with the independence from the uterus, facilitates attachment by the embryo to other surfaces (Davies 1982). (3) There is a fundamentally different type of steroid secretion during the luteal phase in women. Transport of ova through the oviduct is controlled by peristalsis and antiperistalsis; and oestrogens and progestins (which modify the relative importance of these contractions) are responsible for the chronology of egg transport from the fimbrial to the uterus (Thibault 1972). (4) The similarity between the uterine and the tubal environment, together with the fact that the human tube is able to decidualize, may account for the fact that spontaneous ectopic implantations have only been recognized in women, and have proved essentially impossible to detect in animals. (5) Maturational synchrony (between the uterine environment and the development of the blastocyst) is less strictly required in women than in animals; it could account for the spontaneous occurrence of ectopic implantation in women (Lofstedt 1989).

Levasseur (1983) also identified several factors which distinguish women from domestic mammals: (1) in women, the presence of the embryo is not required in the uterus for luteal progesterone secretion to take place; (2) the embryo is capable of surviving in either the tubes or the uterus; (3) the placenta is haemochorial; and (4) implantation is interstitial. All these characteristics are not simultaneously found in any domestic mammal, and it would seem that the more numerous the differences, the less chance there would be of a true extra-uterine pregnancy occurring.

\section{Ectopic pregnancy prevention mechanism}

Pauerstein et al. (1990) suggested that the human fallopian tube lacks a system that functions in the oviducts of other species, such as rabbits (Moore et al. 1992), to prevent oviductal implantation. Pauerstein et al. (1990) postulated the presence of a factor in the endosalpinx of infraprimates that actively suppresses ectopic implantation in the oviduct. This system may be absent or imperfectly developed in the human fallopian tube, and may be further compromized in damaged tubes. Rather than simply being non receptive to implantation, this factor might actively suppress embryo development beyond the blastocyst stage, and thus prevent implantation.

\section{Pathological factors}

It has been regularly proposed that humans are subject to diseases that do not affect other species. These diseases are thought to cause structural damage to the fallopian tubes, which, in turn, either causes the arrest of the embryos in the tube or increased tubal receptivity for implantation (Pauerstein et al. 1990). However, animals also suffer from reproductive diseases that are not presented in humans.

In humans, the invasiveness of placentation and the development of ectopic endometrial tissue (endometriosis) are probably the reasons that it is possible for ectopic pregnancies to become established, thus allowing such fetuses to develop to term (Nack 2000). Endometriosis is not a feature of animals (except primates), and previous attempts to develop non-primate models of extrauterine pregnancy have not met with success (Hunter 2002).

\section{Other proposed factors}

Levasseur (1983) examined other possible factors that could explain the frequency of extrauterine pregnancies in women, and their rarity in domestic mammals. (1) The risk of ectopic pregnancy increases in women with age and parity (Pulkkinen 1995), yet the rotation of females used for reproduction is usually rapid among domestic mammals. (2) Women undergoing surgical interventions for tubal pathology due to congenital conditions, infections or to other causes, have a high ectopic pregnancy rate (Peterson et al. 1997, Paavonen \& Eggert-Kruse 1999), but mammals with tubal pathology do not generally reproduce. (3) Ectopic pregnancies are not observed in domestic animals subjected to experimental tubal surgery. (4) The administration of gonadotrophins in women, but not in mammals, 
to promote ovulation, is associated with a higher rate of ectopic pregnancy. (5) The failure of some types of contraceptives, such as tubal sterilization, or the use of chemical sterilization, such as quinacrine, is associated with ectopic pregnancy in women (Kessel et al. 1985). It has also been reported that the inhalation of cigarette smoke is a risk factor for ectopic pregnancy (Knoll et al. 1995, DiCarlantonio \& Talbot 1999). However, no comparable situation is found in domestic animals.

\section{Management}

In humans, the evaluation of a patient with suspected ectopic pregnancy may include the determination of biochemical markers (serum human chorionic gonadotrophin $(\beta-h C G)$ levels and serum progesterone levels), ultrasonography, and the use of other diagnostic tests, such as uterine curettage, culdocentesis or laparoscopy. The most commonly used methods are the $\beta$-hCG level in combination with ultrasonography. In general, an ectopic pregnancy should be suspected when an empty uterus is seen via transvaginal ultrasonography, and when the $\beta$-hCG level is greater than $1500-2000 \mathrm{mlU}$ per $\mathrm{ml}$ (Tenore 2000, McCollum 2001). However, it has been discussed that a viable intrauterine pregnancy is not excluded in such circumstances, and consequently a 'diagnostic curettage' performed with this indication may lead to an unintended, induced abortion (McCollum 2001).

Once a tubal ectopic pregnancy has been diagnosed, various types of treatments are available: (a) surgical treatment, which can be performed radically or conservatively, either laparoscopically or by an open surgical procedure; (b) medical treatment, with a variety of drugs, which can be administered systemically and/or locally by different routes (transvaginally, either under sonographic or laparoscopic guidance); and (c) expectant management. The choice of treatment modality should be based not only on short-term outcome measures (primary treatment success and reinterventions for clinical symptoms or persistent trophoblast), but also on long-term outcome measures (tubal patency and future fertility) (Hajenius et al. 2000).

The only treatment recorded in the bibliography for ectopic pregnancies in animals is surgical removal, either with or without ovariohysterectomy (Johnson 1986). This may be due to the fact that in most cases, diagnoses tend to be accidental or a necropsy finding. No other treatments for animals appear in the consulted bibliography. Therefore, the following management techniques refer to human beings.

\section{Surgical treatment}

Modern surgery for tubal ectopic pregnancy has two goals: (1) the prevention of mortality and morbidity; and when desired (2) the preservation of fertility (DeCherney \& Boyers 1985). Conservative surgery management is different according to the ectopic pregnancy location. In an ampullary ectopic pregnancy, a linear salpingostomy is performed, and the incision is then left to heal by a secondary intent. In an ectopic pregnancy located at the fimbrial ends, a 'milking' technique allows the trophoblastic tissue to pass through the fimbria. If, however, the ectopic pregnancy is located in the isthmic portion of the fallopian tube, that segment is excised, and the two ends are reanastamosed under microscopic guidance at a later date (Tenore 2000). The distinct anatomic differences between ampulla and isthmus make linear salpingostomy a poor choice in the isthmic tube (DeCherney \& Boyers 1985). Once an ectopic pregnancy has progressed to rupture, the only treatment option is surgery, either laparoscopically or by full laparotomy.

Although laparoscopic conservative surgery is less costly (less blood loss and analgesic requirement, shorter operation times, hospital stays, and convalescence times) than the open surgical approach, it is significantly less successful in eliminating a tubal pregnancy due to the higher persistent trophoblast rate of laparoscopic surgery (Hajenius et al. 2000).

The most frequent complications of surgery are the recurrence of an ectopic pregnancy (with an incidence range between $5 \%$ and $20 \%$ ), and the incomplete removal of trophoblastic tissue. It has been suggested for very high-risk patients that a single dose of methotrexate should be given postoperatively as a prophylactic measure (Hajenius et al. 1997).

\section{Medical treatment}

Early-stage diagnosis has made the medical management of ectopic pregnancies an option. The potential advantages are the avoidance of surgery and its concomitant hazards, the preservation of tubal patency and function, and lower cost (Tenore 2000). Chemical agents that have been investigated include hyperosmolar glucose, urea, cytotoxic agents (e.g. methotrexate and actinomycin), prostaglandins and mifepristone (RU486) (Vejtorp et al. 1991, Anandakumar et al. 1995, Strohmer et al. 1998). Methotrexate, a folic acid antagonist that interferes with DNA synthesis and cell multiplication, has been the object of most studies. Rapidly dividing cells are most vulnerable to methotrexate. This accounts for the effect the drug has on trophoblastic tissue, and also for its side effects on the buccal and intestinal mucosa, urinary bladder, bone marrow and skin. Although a potential for serious toxic effects exists, the low dosages of methotrexate used in patients with ectopic pregnancies generally cause only mild, self-limited reactions. Common side effects include nausea and vomiting, urinary frequency and mild diarrhoea. Thus, when the diagnosis is certain, and the largest dimension of an ectopic mass is less than $3.5 \mathrm{~cm}$, methotrexate therapy becomes an option. However, the $\beta$-hCG level needs to be considered when selecting patients for methotrexate therapy 
(Tenore 2000). Corsan et al. (1995) reported that $\beta$-hCG levels higher than $1500 \mathrm{mlU}$ per $\mathrm{ml}$ were associated with a much higher risk of treatment failure, and that $\beta$-hCG levels higher than $5000 \mathrm{mlU}$ per $\mathrm{ml}$ did not usually respond to methotrexate therapy. Nonetheless, Yuce et al. (2004) described a case of an unruptured ectopic pregnancy in a patient with extremely high $\beta$-hCG concentrations $(38270 \mathrm{mlU}$ per $\mathrm{ml}$ ) which was successfully managed with a single dose of methotrexate.

In addition to $\beta$-hCG levels, indications for methotrexate include haemodynamic stability, confirmation of ectopic pregnancy by ultrasound examination, significant risk associated with general anaesthesia, patient compliance, lack of contraindications to methotrexate therapy, smallsized ectopic mass, and lack of fetal cardiac motion (Tenore 2000).

The bibliography refers to other alternative, or new, treatments. It has been reported that the administration of an anti-progesterone may result in the safe disruption of an early ectopic pregnancy and tubal abortion through the fimbrial end of the uterine tube, or in the resorption of the ectopic gestation as a result (Ulmann \& Dubois 1988). It has been suggested that the vascular endothelial growth factor (VEGF) may be the angiogenic factor responsible for the implantation and placentation of an ectopic pregnancy in the human oviduct. The inhibition of VEGF action may also be a potential medical treatment for ectopic pregnancy (Lam et al. 2004). It has been reported that the systemic application of 5 -aminolevulinic acid followed by transmural exposure to photoactivating light $(630 \mathrm{~nm})$, resulted in the resorption of early pregnancies in the rat. This approach was proposed as a new treatment for ectopic pregnancy (Yang et al. 1994). The vaginosonographically guided application of hyperthermia to an early detected human ectopic pregnancy has been proposed as a promising future therapy (Popp et al. 1993). It has recently been reported that unruptured live ectopic pregnancies may be successfully managed without surgical intervention through an ultrasound-guided local injection of either methotrexate or potassium chloride (Monteagudo et al. 2005).

\section{Expectant management}

There have been reports of the spontaneous resolution of ectopic pregnancies in both humans and animals, suggesting that many early stage diagnosed cases need no treatment at all (Mashiach et al. 1982, Thursby-Pelham 1992). In humans, it has been reported that expectant management may be an option for the asymptomatic patient with a small-sized ectopic pregnancy (less than $3.5 \mathrm{~cm}$ in greatest dimension), and when $\beta$-hCG levels are low and declining (Sauer et al. 1988, Tenore 2000).

Regardless of the treatment approach (surgical, medical or expectant), the $\beta$-hCG level should be followed until it becomes undetectable or until it decreases to less than $5 \mathrm{mlU}$ per $\mathrm{ml}$ (Tenore 2000).
In conclusion, several differences between primates (human and non human) and animals suffering ectopic pregnancies exist, mainly in the location where this condition is developed. The scarcity of reports about this condition in commercial animals might be due to the absence of ordinary necropsy procedures. Extrauterine pregnancies would not be such an unusual finding if we were to perform regular necropsies on animals. Different species have successfully been used as animal models in ectopic pregnancy studies, mainly for the evaluation of new treatments and surgical techniques (Nelson et al. 1986, Tepper et al. 1992, Popp et al. 1993) that have later been used in human beings. However, it is necessary to clarify several aspects such as the aetiology of this condition and the implicated factors.

\section{Acknowledgements}

The author is grateful to the Cardenal Herrera-CEU University and Generalitat Valenciana for their financial support (PRUCH02/25, PRUCH04/11 and GV05/202), and to the members of the Histology and Anatomy pathology unit for their collaboration. The author declares that there is no conflict of interest that would prejudice the impartiality of this scientific work.

\section{References}

Anandakumar C, Choolani MA, Adaikan PG, Wong YC, Gopal M, Marshall B \& Ratnam SS 1995 Combined chemotherapy in the medical management of tubal pregnancy. Australia and New Zealand Journal of Obstetrics and Gynaecology 35 437-440.

Araujo P 1964 A case of ectopic abdominal pregnancy in guinea pig. Laboratory Animal Care 14 1-5.

Arvidsson A 1998 Extra-uterine pregnancy in a rabbit. Veterinary Record 142176.

Bai SX, Wang YL, Qin L, Xiao ZJ, Herva R \& Piao YS 2005 Dynamic expression of matrix metalloproteinases (MMP-2, -9 and -14) and the tissue inhibitors of MMPs (TIMP-1, -2 and -3 ) at the implantation site during tubal pregnancy. Reproduction 129 103-113.

Bazer FW \& First NL 1983 Pregnancy and parturition. Journal of Animal Science 57 (Suppl 2) 425-460.

Beddow BA 1999 Ectopic pregnancy in a rabbit. Veterinary Record 144624.

Bland KP \& Donovan BT 1965 Experimental ectopic implantation of eggs and early embryos in guinea-pigs. Journal of Reproduction and Fertility 10 189-196.

Bland-Sutton J 1904 Abdominal pregnancy in women, cats, dogs and rabbits. Lancet ii 1625-1627.

Bloch S 1962 An atypical pregnancy in a laboratory mouse. Acta Anatomica 51 148-152.

Bosu WT \& Barker IK 1980 An abdominal mummified fetus in a Macaca assamensis. Journal of Medical Primatology 9 71-75.

Botcherby WC 1980 Ectopic pregnancy in a cow. Veterinary Record $106565-566$.

Bouyer J, Coste J, Fernandez H, Pouly JL \& Job-Spira N 2002 Sites of ectopic pregnancy: a 10-year population-based study of 1800 cases. Human Reproduction 17 3224-3230.

Buckley P \& Caine A 1979 A high incidence of abdominal pregnancy in the Djungarian hamster (Phodopus sungorus). Journal of Reproduction and Fertility 56 679-682.

Bunte RM \& Hildebrandt PK 1975 Abdominal mummified fetus in an owl monkey. Journal of the American Veterinary Medical Association $167667-668$. 
Carrig CB, Gourley IM \& Philbrick AL 1972 Primary abdominal pregnancy in a cat subsequent to ovariohysterectomy. Journal of the American Veterinary Medical Association $160308-310$.

Climent S \& Bascuas JA 1989 Embriología general. Aparato locomotor: generalidades. In Cuadernos de Anatomía y Embriología Veterinaria, 2nd edn, pp 78-85. Eds S Climent \& JA Bascuas. Madrid: Editorial Marbán.

Corsan GH, Karacan M, Qasim S, Bohrer MK, Ransom MX \& Kemmann E 1995 Identification of hormonal parameters for successful systemic single-dose methotrexate therapy in ectopic pregnancy. Human Reproduction 10 2719-2722.

Coste J, Bouyer J, Germain E, Ughetto S, Pouly JL \& Job-Spira N 2000 Recent declining trend in ectopic pregnancy in France: evidence of two clinicoepidemiologic entities. Fertility and Sterility $74881-886$

Crownover RW \& Yeargan GS Jr 1976 Extra-uterine pregnancy in a spayed cat. Veterinary Medicine, Small Animal Clinician 71 1698-1699.

Davies PT 1982 Extrauterine pregnancy in a ewe. Veterinary Record 110475.

De Cecco L, Capitanio GL, Croce S, Forcucci M, Gerbaldo D \& Rissone R 1984 Biology of nidation and ectopic implantation. Acta Europaea Fertilitatis 15 347-355.

De Nooy PP 1979 Extrauterine pregnancy and severe ascites in a cat. Veterinary Medicine, Small Animal Clinician 74 349-350.

DeCherney AH \& Boyers SP 1985 Isthmic ectopic pregnancy: segmental resection as the treatment of choice. Fertility and Sterility 44 307-312.

DiCarlantonio G \& Talbot P 1999 Inhalation of mainstream and sidestream cigarette smoke retards embryo transport and slows muscle contraction in oviducts of hamsters (Mesocricetus auratus). Biology of Reproduction 61 651-656.

Douglas CP 1963 Tubal ectopic pregnancy. British Medical Journal $5361838-841$.

Feeney DA \& Johnston GR 1983 The uterus. In Veterinary Pathology, 5th edn, p 1536. Eds TC Jones \& RD Hunt. Philadelphia: Lea \& Febiger.

Forbes NA 1989 Ectopic pregnancy in a cat. Veterinary Record 124595.

Freytag K 1972 Secondary abdominal pregnancy in a mare. Deutsch Tierarztliche Wochenschrift 79 522-524.

Ginsburg KA, Quereshi F, Thomas M \& Snowman B 1989 Intramural ectopic pregnancy implanting in adenomyosis. Fertility and Sterility 51 354-356.

Gosden RG \& Russell JA 1981 Spontaneous abdominal implantation in the rat with development to full term. Laboratory Animal $\mathbf{1 5}$ $379-380$.

Hajenius PJ, Engelsbel S, Mol BW, Van der Veen F, Ankum WM, Bossuyt PM, Hemrika DJ \& Lammes FB 1997 Randomised trial of systemic methotrexate versus laparoscopic salpingostomy in tubal pregnancy. Lancet $350774-779$.

Hajenius PJ, Mol BW, Bossuyt PM, Ankum WM \& Van Der Veen F 2000 Interventions for tubal ectopic pregnancy. Cochrane Database of Systematic Reviews 2 CD000324.

Hanes MV 1964 Ectopic pregnancy following total hysterectomy. Report of a case. Obstetrics and Gynecology 23 882-884.

Hannon CA 1981 Mummified fetuses in a cat. Modern Veterinary Practice 62 133-134.

Hansen JS 1974 Ectopic pregnancy in a queen with one uterine horn and a urachal remnant. Veterinary Medicine, Small Animal Clinician 69 1135-1137.

Heap RB, Flint AP \& Gadsby JE 1979a Role of embryonic signals in the establishment of pregnancy. British Medical Bulletin 35 129-135.

Heap RB, Flint AP, Gadsby JE \& Rice C 1979b Hormones, the early embryo and the uterine environment. Journal of Reproduction and Fertility 55 267-275.

Hedge D 1989 Extrauterine fetal development. Journal of the American Veterinary Medical Association 1941522.
Hong CC \& Armstrong ML 1978 Ectopic pregnancy in 2 guinea-pigs. Laboratory Animal 12 243-244.

Hreshchyshyn MM \& Hreshchyshyn LO 1964 Experimentally induced abdominal pregnancy in mice. American Journal of Obstetrics and Gynecology 89 829-830.

Hunter RH 1998 Have the Fallopian tubes a vital role in promoting fertility? Acta Obstetrica et Gynecologica Scandinavica 77 475-486.

Hunter RH 2002 Tubal ectopic pregnancy: a patho-physiological explanation involving endometriosis. Human Reproduction $\mathbf{1 7}$ $1688-1691$.

Iffy L 1965 Embryologic studies of time of conception in ectopic pregnancy and first-trimester abortion. Obstetrics and Gynecology 26 490-498.

Jerome CP \& Hendrickx AG 1982 A tubal pregnancy in a rhesus monkey (Macaca mulatta). Veterinary Pathology 19 239-245.

Johnson CA 1986 Disorders of pregnancy. Veterinary Clinics of North America Small Animal Practise 16 477-482.

Kalof AN, Fuller B \& Harmon M 2004 Splenic pregnancy: a case report and review of the literature. Archives of Pathology \& Laboratory Medicine 128 e146-e148.

Kessel E, Zipper J \& Mumford SD 1985 Quinacrine nonsurgical female sterilization: a reassessment of safety and efficacy. Fertility and Sterility $4 \mathbf{4} 293-298$.

King IR, Myers JD \& Semmer JR 1978 Diagnosis of unruptured ectopic pregnancy by the use of the laparoscope. Journal of the Tennessee Medical Association 71 19-21.

Knoll M, Shaoulian R, Magers T \& Talbot P 1995 Ciliary beat frequency of hamster oviducts is decreased in vitro by exposure to solutions of mainstream and sidestream cigarette smoke. Biology of Reproduction 53 29-37.

Knott CD 1989 Ectopic pregnancy in a cat. Veterinary Record 124666. Kompanje EJ 2005 A remarkable case in the history of obstetrical surgery: a laparotomy performed by the Dutch surgeon Abraham Cyprianus in 1694. European Journal of Obstetrics, Gynaecology and Reproductive Biology 118 119-123.

Kraiem J, Bouden S, Ounaissa F \& Falfoul A 2004 Ovarian pregnancy: the situation in 2003. A report of four cases and literature review. La Tunsie Medicale 82 858-866.

Kucera E, Madar J, Jirasek JE \& Chaloupkova A 2004 Immunopathological and histopathological aspects of ectopic implantation with possible effect on fertility disorders. Ceska Gynekologie 69 (Suppl 1) 3-8.

Lam PM, Briton-Jones C, Cheung CK, Leung SW, Cheung LP \& Haines C 2004 Increased messenger RNA expression of vascular endothelial growth factor and its receptors in the implantation site of the human oviduct with ectopic gestation. Fertility and Sterility 82 686-690.

Lapin BA \& Yakovleva LA 1963 In Comparative Pathology in Monkeys, pp 215-216. Eds BA Lapin \& LA Yakovleva. Illinois: Charles C. Thomas, Springfield.

Lederer HA \& Fisher LE 1960 Ectopic pregnancy in a dog. Journal of the American Veterinary Medical Association 13761.

Levasseur MC 1983 Putative causes of the frequency of extra-uterine pregnancy in women and its rarity in domestic mammals. Contraception, Fertilitie, Sexualite (Paris) 11 1207-1213.

Lofstedt R 1989 Questions extrauterine development of fetuses. Journal of the American Veterinary Medical Association 194 326-327.

McClure HM \& Chang J 1975 Ectopic pregnancy in a squirrel monkey. Journal of the American Veterinary Medical Association $167654-655$.

McCollum JS 2001 Diagnostic curettage in the evaluation of ectopic pregnancy. American Family Physician 63 222-225.

Madani MO \& Tirgari M 1984 Extrauterine pregnancy in a ewe. Veterinary Record 115 547-548.

Marcato PS \& Rosmini R 1986 In Pathology of the Rabbit and Hare. A Color Atlas and Compendium, pp 185-186. Eds PS Marcato \& R Rosmini. Bologna: Societa editrice esculapio. 
Mashiach S, Carp HJ \& Serr DM 1982 Nonoperative management of ectopic pregnancy. A preliminary report. Journal of Reproduction and Medicine 27 127-132.

Maxwell JP, Eastman NJ \& Smetana H 1927 Primary abdominal pregnancy. Surgery, Gynecology \& Obstetrics 12 802-804.

Mitchell KW 1989 Ectopic pregnancy in a ewe. Veterinary Record 124498.

Monteagudo A, Minior VK, Stephenson C, Monda S \& Timor-Tritsch IE 2005 Non-surgical management of live ectopic pregnancy with ultrasound-guided local injection: a case series. Ultrasound in Obstetrics \& Gynecology 25 282-288.

Moor RM \& Rowson LE 1966a Local maintenance of the corpus luteum in sheep with embryos transferred to various isolated portions of the uterus. Journal of Reproduction and Fertility 12 539-550.

Moor RM \& Rowson LE $1966 b$ The corpus luteum of the sheep: effect of the removal of embryos on luteal function. Journal of Endocrinology 34 497-502.

Moore GD, Eddy CA \& Pauerstein CJ 1992 Rabbit endosalpinx inhibits implantation in vitro. Fertility and Sterility 57 902-907.

Myers RE 1972 The pathology of the rhesus monkey placenta. Acta Endocrinologica Suppl 166 221-257.

Nack RA 2000 Theriogenology question of the month. An ectopic fetus. Journal of the American Veterinary Medical Association $217182-184$.

Nelson LM, Margara RA \& Winston RM 1986 Primary and secondary closure of ampullary salpingotomy compared in the rabbit. Fertility and Sterility 45 292-295.

Nicosia SV 1985 Pathology of the oviducts and embryonal remnants. Obstetrics and Gynecology Annual 14 382-410.

Onan MA, Turp AB, Saltik A, Akyurek N, Taskiran C \& Himmetoglu O 2005 Primary omental pregnancy: case report. Human Reproduction $20807-809$.

Owensby T, Jackson K \& Scharf B 2001 Failure to deliver in a rabbit with intra-abdominal masses. Laboratory Animal 30 23-25.

Paavonen J \& Eggert-Kruse W 1999 Chlamydia trachomatis: impact on human reproduction. Human Reproduction Update 5 433-447.

Palmer NE 1989 Ectopic pregnancy in a cat. Veterinary Record 12524.

Pauerstein CJ, Eddy CA, Koong MK \& Moore GD 1990 Rabbit endosalpinx suppresses ectopic implantation. Fertility and Sterility $\mathbf{5 4}$ $522-526$

Peters LJ 1982 Abdominal pregnancy in a golden hamster (Mesocricetus auratus). Laboratory Animal Science 32 392-393.

Peterson HB, Xia Z, Hughes JM, Wilcox LS, Tylor LR \& Trussell J 1997 The risk of ectopic pregnancy after tubal sterilization. US Collaborative Review of Sterilization Working Group. New England Journal of Medicine $336762-767$.

Polzenhagen A, Karasek E \& Hegermann I 1983 Extrauterine pregnancy in a rat. Zeitschrift fur Versuchstierkunde 25 183-184.

Popp LW, Gaetje R, Status S \& Lierse W 1993 A rabbit model for the evaluation of minimal access treatment of ectopic pregnancy in humans, using intrachorionic injection and local hyperthermia. Clinical and Experimental Obstetrics and Gynecology 20 226-235.

Pulkkinen MO 1995 Oviductal function is critical for very early human life. Annals of Medicine 27 307-310.

Rosell JM 2000 Enfermedades. In Enfermedades del Conejo, pp 93. Ed. JM Rosell. Madrid: Grupo Mundi-Prensa.

Sauer MV, Rand TC \& Buster JE 1988 Ectopic pregnancy without laparotomy: defining the incidence of manageable patients. International Journal of Gynaecology and Obstetrics 27 247-248.

Schlabritz-Loutsevitch NE, Hubbard GB, Frost PA, Cummins LB, Dick EJ Jr, Nathanielsz PW \& McDonald TJ 2004 Abdominal pregnancy in a baboon: a first case report. Journal of Medical Primatology 33 55-59.

Segura Gil P, Peris Palau B, Martinez Martinez J, Ortega Porcel J \& Corpa Arenas JM 2004 Abdominal pregnancies in farm rabbits. Theriogenology 62 642-651.

Smith HA, Jones TC \& Hunt RD 1974 In Veterinary Pathology, 4th edn, Philadelphia, Pennsylvania: Lea and Febiger.

Smith CA, Stone DM \& Prieur DJ 1989 Spontaneous profuse superovulation in association with ectopic fetuses in a rabbit. Laboratory Animal Science 39 74-77.

Strohmer H, Obruca A, Lehner R, Egarter C, Husslein P \& Felchtinger W 1998 Successful treatment of a heterotopic pregnancy by sonographically guided instillation of hyperosmolar glucose. Fertility and Sterility 69 149-151.

Tarim E, Ulusan S, Kilicdag E, Yildirim T, Bagis T \& Kuscu E 2004 Angular pregnancy. Journal of Obstetric and Gynaecological Research $30377-379$.

Tenore JL 2000 Ectopic pregnancy. American Family Physician 61 1080-1088.

Tepper R, Nahum R, Rahamim E, Kapolovitz Y, Segal Y, Karib N \& Beyth Y 1992 Effects of methotrexate on rabbit oviducts and on cell cultures of bovine oviduct epithelium. Gynecologic and Obstetric Investigation 33 65-68.

Thibault C 1972 Some pathological aspects of ovum maturation and gamete transport in mammals and man. Acta Endocrinologica Suppl 166 59-66.

Thursby-Pelham RH 1992 Mare scanning - possible ectopic pregnancy. Veterinary Record 130500.

Ulmann A \& Dubois C 1988 Anti-progesterones in obstetrics, ectopic pregnancies and gynaecological malignancy. Baillier's Clinical Obstetrics and Gynaecology 2 631-638.

Van Den Eeden SK, Shan J, Bruce C \& Glasser M 2005 Ectopic pregnancy rate and treatment utilization in a large managed care organization. Obstetrics and Gynecology 105 1052-1057.

Vejtorp M, Vejerslev LO \& Ruge S 1991 Treatment of tubal pregnancy by local injection of prostaglandin: selection of patients and evaluation of subsequent tubal patency. European Journal of Obstetrics, Gynaecology and Reproductive Biology 41 85-90.

Waldeyer W 1893 Ueber eine ectopische Schwangershaft bei einem Mantelpavian Zeits. Zeitschrift für Geburtshilfe und Gynäkologie 27 177-181.

Wolfman W \& Holtz G 1983 Update on ectopic pregnancy. Canadian Medical Association Journal 129 1265-1269.

Xiao GH, Chen DJ, Sun XF, She RQ \& Mai YM 2005 Abdominal pregnancy: full-term viable baby. European Journal of Obstetrics, Gynaecology and Reproductive Biology 118 117-118.

Yang JZ, Van Vugt DA, Melchior MF, Hahn PM \& Reid RL 1994 Photodynamic ablation of early pregnancy in the rat with 5 -aminolevulinica acid: a potential new therapy for tubal ectopic pregnancy in the human. Fertility and Sterility 62 1060-1065.

Yuce MA, Gucer F, Balkanli-Kaplan P \& Sayin NC 2004 Medical management of ectopic pregnancy with extremely high beta-hCG levels: a case report. Clinical and Experimental Obstetrics and Gynecology 31 242-243.

Received 23 June 2005

First decision 5 August 2005

Revised manuscript received 26 September 2005

Accepted 3 October 2005 